\title{
Growth Control of $\mathrm{SnO}_{2}$ Nanoparticles Using a Low-Temperature Solution Process
}

\author{
Catlin Ethridge1, Lucas Splingaire, Holly Korte1, Udo Schnupf, Kazuhiro Mansekiz, Takashi \\ Sugiura3, Saeid Vafaei1* \\ 1Mechanical Engineering Department, Bradley University, Peoria, IL, USA \\ 2Mund-Lagowski Department of Chemistry and Biochemistry, Bradley University, Peoria, IL, USA \\ 3Department of Chemistry and Biomolecular Science, Gifu University, Gifu, Japan
}

\begin{abstract}
Perovskite solar cells, specifically using $\mathrm{SnO}_{2}$ nanoparticles, have been extensively researched and are proving to be extremely promising in the field of renewable energy by increasing a solar cell's overall efficiency and lowering the cost of production. In this study, an experiment was performed to synthesize $\mathrm{SnO}_{2}$ nanoparticles over 8 days. Day 1 was the synthesis which included the mixing of water, tin (II) chloride, methanol, sodium carbonate and dimethylformamide and then heated in a water bath at $28^{\circ} \mathrm{C}$. Sampling of this solution started on day 4 of the experiment when sufficient particle growth was observed and stopped at day 8 . Centrifuging, freezing, and freezedrying were used for each sample to isolate the solid product. Transmission electron microscopy and X-ray powder diffraction was used to characterize the isolated nanoparticle. The results from the X-ray powder diffraction showed that each sample consisted of $\mathrm{SnO}_{2}$ nanoparticles of different sizes. From the transmission electron microscopy on the samples showed that the overall size of the nanoparticles gradually increased during each additional synthesis day.
\end{abstract}

KEY WORDS: $\mathrm{SnO}_{2}$, Nanoparticles, Freeze-Drying, Solar cells

\section{INTRODUCTION}

The ever increasing worldwide need for energy and environmental problems caused by fossil fuel use spawned an urging need for clean energy. This has led to a rapid hike in the development of renewable energy sources with solar power being one of the major candidates due to the sun being able to provide the ultimate solution to the challenge of sustainable energy supply. Generally, in a solar cell, electrons are released when the solar cell is hit by light; the electrons are then collected by the solar cell. There two common methods to generate solar power via solar cells and passive/active solar thermal systems. Focusing on the solar cells for electric power generation, there are different ways to harvest the solar energy of which the conventional solid-state solar panels are the most common. The cons of these silicon based solar panels are their production costs and their negative environmental impact. In recent years, different variations of solar cells have emerged promising low production costs and low environmental impact and of high efficiency such as perovskite solar cells (PSC) and dye-sensitized solar cells (DSSC). In these types of solar cells, one of the photo electrodes is composed of nano-crystalline material such as $\mathrm{TiO}_{2}$ and/or $\mathrm{SnO}_{2}$, forming the semiconductor layer for the photon-electron transfer process. The nano-crystalline material is placed on a transparent conducting glass in order to achieve a high specific surface area. This surface area is essential for the absorption of dye molecules or perovskite film which in turn plays a significant role in the amount of light that can be harvested by the solar cell [1]. Specifically, for the design of a DSSC a mesoporous layer is formed when the nanostructure of the DSSC is filled with dye [2], in which the dye acts as photon absorber and the nanostructure as electrons 
transmitter. The arrangement of the nanostructure and the electron transport efficiency are both components that are considered when improving the overall efficiency of the devices. The nanostructure arrangement and electron transport efficiency are key elements that require optimization to balance increased surface area for dye absorption with a decrease in transport efficiency. In PSC, the perovskite layer acts as a light absorber.

Recently, another metal oxide, tin(IV) oxide $\left(\mathrm{SnO}_{2}\right)$ has been explored as potential photo anodic material as an alternative to $\mathrm{TiO}_{2}$. $\mathrm{SnO}_{2}$ has been well studied for example in connection with perovskite solar cells (PSCs) mostly due to its favorable attributes such as high electron mobility $\sim 100-200 \mathrm{~cm}_{2} \mathrm{~V}_{-1} \mathrm{~s}-1$ ) and wide bandgap of $3.6 \mathrm{eV}$ compared to $3.2 \mathrm{eV}$ for $\mathrm{TiO}_{2}$. The high mobility promotes faster transport of photo injected electrons and thereby reducing the recombination probability of photo induced electrons. In addition, $\mathrm{SnO}_{2}$ forms a homo junction with the FTO substrate and thus resolves the high contact resistance issue as observed in heterojunctions formed with other oxides like $\mathrm{TiO}_{2}$. Despite the apparent advantages over $\mathrm{TiO}_{2}$ there are some concerns using $\mathrm{SnO}_{2}$ as electron transport layer and the main concern is that it suffers from degradation at higher temperature processes. Much research has been done to show that the efficiency of solar cells can be increased further using $\mathrm{SnO}_{2}$ rather than $\mathrm{TiO}_{2}$.

Of particular importance is to understand the relationship between $\mathrm{SnO}_{2}$ structures and PSC performance. Synthesis of $\mathrm{SnO}_{2}$ is thus one of the crucial issues in the development of high efficiency PSC. There are many different synthesis methods described in the literature how to obtain nanoparticles of which three are commonly used: hydrothermal, solvothermal, and sol-gel methods. In the hydrothermal synthesis an autoclave is used to heat an aqueous reaction mixture at high pressures. In general, temperature, pressure, and reaction time are variables used to control the growth of the nanoparticles. Specifically, it allows the synthesis of exact size and shape distributions. The solvothermal method is analog to the hydrothermal method except that they are carried out in non-aqueous media. The disadvantage of these two methods is the high temperature and pressure, and the high cost of the autoclave to run at temperatures and pressures of up to $300^{\circ} \mathrm{C}$ and $10 \mathrm{bar}$, respectively [3,4]. The sol-gel method (chemical solution deposition) avoids the previously mentioned disadvantages and is a well-established synthetic approach for the preparation of metal oxides. In general, this process involves several steps: hydrolysis (metal precursor) and condensation, formation of 3D-gels, aging/growth, drying, densification, and crystallization. The sol-gel method can be carried out in aqueous and non-aqueous media. The disadvantages of the sol-gel method can be the cost of the raw-materials, such as metal-alkoxides precursors, and the annealing process to eliminate the organics from the oxide.

There have been a series of recent publication in the literature using $\mathrm{SnO}_{2}$ in the production of PSCs. Yang et al. [5] investigated the efficiency using an EDTA-complexed $\mathrm{SnO}_{2}$ (E-SnO 2$)$ by mixing ethylenediaminetetraacetic acid (EDTA) with deionized water (DI) in the PSC. To characterize the E-SnO2, Yang et al. used X-ray photoelectron spectra (XPS) and atomic force microscopy (AFM). With XPS, the particles were studied after deposition on the quartz substrates. An $\mathrm{AMF}$ of the $\mathrm{E}_{-} \mathrm{SnO}_{2}$ films showed that they had a root-mean-square roughness of $2.88 \mathrm{~nm}$. For $\mathrm{SnO}_{2}$ the electron mobility was found to be $9.92 \times 10-4 \mathrm{~cm}_{2}$ $\mathrm{V}_{-1} \mathrm{~s}-1,3.56 \times 10_{-5} \mathrm{~cm}_{2} \mathrm{~V}_{-1} \mathrm{~S}-1$ for EDTA, and $2.27 \times 10_{-3} \mathrm{~cm}_{2} \mathrm{~V}_{-1} \mathrm{~s}-1$ for $\mathrm{E}_{-} \mathrm{SnO}_{2}$. Overall they found that the tested PSCs had an efficiency of $16.4 \%$ - $21.6 \%$ depending on the construction of the PSC. Liu et al. [6] studied the effects of $\mathrm{SnO}_{2}$ in perovskite solar cells (PSC) using a $\mathrm{SnO}_{2}$ colloidal dispersion solution in water (68\%wt) instead of the organic metallic E-SnO 2 complex. Analysis of their PSC via XRD showed that their sample had large grains, good crystallinity, and reduced grain boundaries. Their PSC's efficiency ranged from $20 \%$ to $21.3 \%$ when compared to bare $\mathrm{SnO}_{2}$. A study done by $\mathrm{Yi}$ et al. [7] showed another example of $\mathrm{SnO}_{2}$ being used in solar cells, with three PSCs prepared and compared: sol-gel $\mathrm{SnO}_{2}\left(\mathrm{~S}-\mathrm{SnO}_{2}\right)$, nano- $\mathrm{SnO}_{2}(\mathrm{~N}-$ $\left.\mathrm{SnO}_{2}\right)$, and bilayer $\mathrm{SnO}_{2}\left(\mathrm{~B}-\mathrm{SnO}_{2}\right)$ which included one layer of $\mathrm{S}-\mathrm{SnO}_{2}$ and one layer of $\mathrm{N}-\mathrm{SnO}_{2}$. A gas quenching method was used on all their PSCs. The results from this experiment determined that the optimum $\mathrm{S}-\mathrm{SnO}_{2} \mathrm{PSC}$ was $0.15 \mathrm{M}$ with a thickness of $35 \mathrm{~nm}$; the observed perovskite cell efficiency (PCE) was 12.97 $\%$ with a fill factor (FF) of $57.6 \%$ and an average visible transmittance (AVT) of $83.47 \%$. The optimum N$\mathrm{SnO}_{2} \mathrm{PSC}$ was $1 \%$ w/v with a thickness of $15 \mathrm{~nm}$ that produced PCE of $14.05 \%$ with an FF of $61.44 \%$ and AVT of $84.57 \%$. In the end, the better option was the bilayer- $\mathrm{SnO}_{2} \mathrm{PSC}$ that was optimized at $0.15 \mathrm{M}, 35 \mathrm{~nm}$ thickness $\mathrm{S}_{-} \mathrm{SnO}_{2}$ and $1 \% \mathrm{w} / \mathrm{v}, 15 \mathrm{~nm}$ thickness $\mathrm{N}-\mathrm{SnO}_{2}$ that increased PCE from $12.97 \%$ to $16.84 \%$ with a FF of $71.25 \%$ and AVT of $83.51 \%$. In the $\mathrm{B}_{-} \mathrm{SnO}_{2} \mathrm{PSC}$ the nanoparticles filled the pin holes of the sol-gel layer and produced better crystallinity and less dislocation. It also produced higher electron mobility and a 
lower electron trap density. Lastly, in the experiment performed by Xie et al. [8] consisted of using a precursor solution to developing a $\mathrm{TiO}_{2}-\mathrm{SnO}_{2}$ bilayer PSC. To analyze the $\mathrm{SnO}_{2}$ nanoparticles, TEM and XRD were used. It was found that the nanoparticles size ranged from 3 to $5 \mathrm{~nm}$ with a lattice fringe interplane $\mathrm{d}$ spacing of $343 \mathrm{~nm}$. The grain size stretched from 3 to $6 \mathrm{~nm}$. The $\mathrm{PCE}$ of the $\mathrm{SnO}_{2} \mathrm{PSC}$ was found to be $15.29 \%$, while it was $12.07 \%$ for $\mathrm{TiO}_{2}$ and $17.19 \%$ for $\mathrm{TiO}_{2}-\mathrm{SnO}_{2}$, meaning the $\mathrm{TiO}_{2}-\mathrm{SnO}_{2} \mathrm{PSC}$ was the most efficient.

The motivation for this research was to develop a method of low temperature synthesis for $\mathrm{SnO}_{2}$ and to determine the optimum reaction time (growth time) for the formation of $\mathrm{SnO}_{2}$ nanoparticles for the use in PSCs. In addition, we used a freeze-dry method to remove the excess solvent from the solid nanoparticles. In the following sections the synthesis strategies used as well as the results of the study are presented.

\section{EXPERIMENTAL}

In the previously mentioned studies, $\mathrm{SnO}_{2}$ was developed using EDTA by Yang et al. and $\mathrm{SnCl}_{4} * 5 \mathrm{H}_{2} \mathrm{O}$ by $\mathrm{Yi}$ et al. In this experiment, the $\mathrm{SnO}_{2}$ particles were synthesized using ultra-pure water (UP-water), methanol, tin (II) chloride $\left(\mathrm{SnCl}_{2}\right)$, sodium carbonate $\left(\mathrm{Na}_{2} \mathrm{CO}_{3}\right)$, and dimethyl formamide (DMF). First $300 \mathrm{~mL}$ UP-water and $300 \mathrm{~mL}$ methanol were mixed in a $1000 \mathrm{~mL}$ glass beaker then $6 \mathrm{~g}$ of $\mathrm{SnCl}_{2}$ were added and dissolved. Secondly, $6 \mathrm{~g}$ of $\mathrm{Na}_{2} \mathrm{CO}_{3}$ were dissolved separately from the previous mixture in a beaker of UP-water (300 $\mathrm{mL}$ ) using a sonic bath. DMF was then carefully added to the $\mathrm{Na}_{2} \mathrm{CO}_{3}$ solution under a hood. This solution was then slowly added to UP-water/methanol/ $\mathrm{SnCl}_{2}$ mixture from the first step. The final solution (reaction mixture), shown in Figure 1, was left to stir, using a magnetic stirrer, for 3 days in a water bath set to $28^{\circ} \mathrm{C}$ before the first sample was taken.

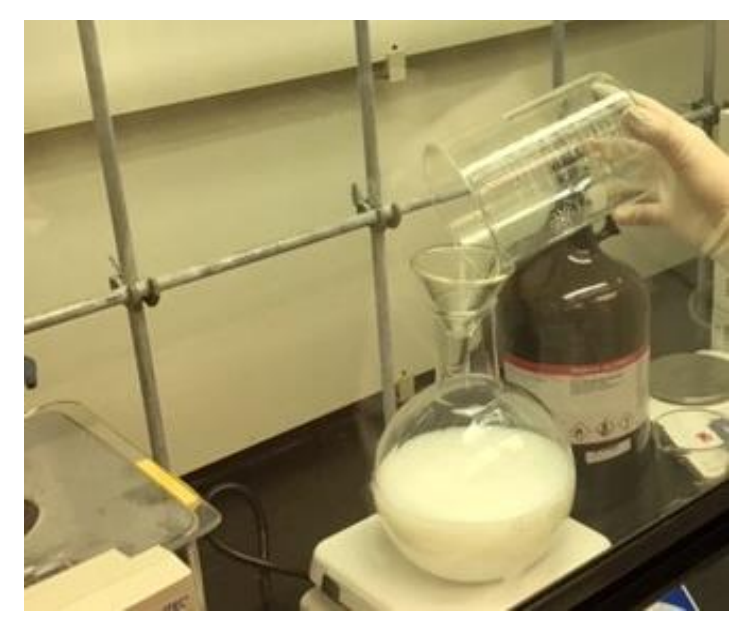

Fig. 1: Final $\mathrm{SnO}_{2}$ solution before placing in the water bath at $28^{\circ} \mathrm{C}$ Initial reaction resulted in a white milky solution. 
Sampling was done by centrifuging (Figure 2) approximately $200 \mathrm{~mL}$ of the reaction mixture at $4000 \mathrm{rpm}$ for 10 minutes, to remove the liquid from the solid. After sampling was completed each time, the flask was returned to the hot water bath at $28^{\circ} \mathrm{C}$ and continued to stir for another $24 \mathrm{hrs}$ for the next sampling.

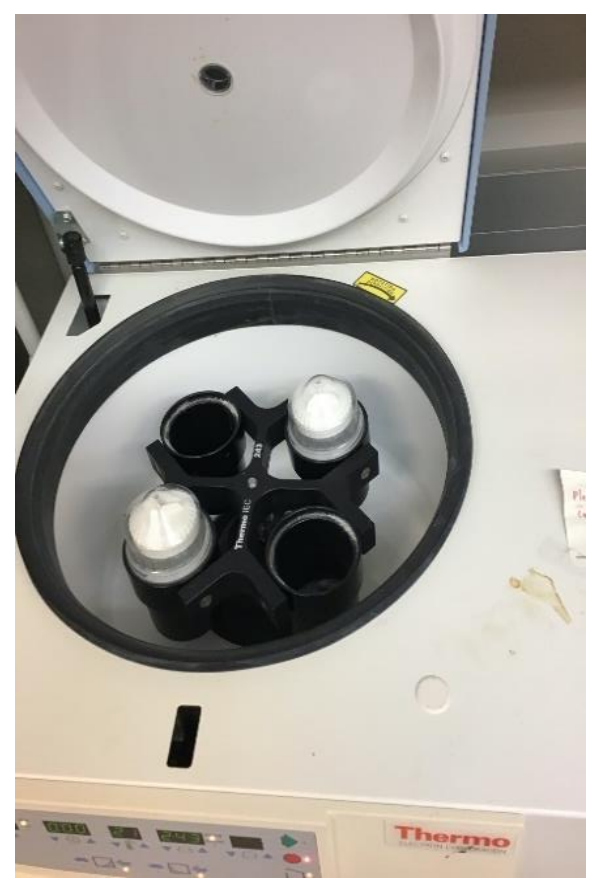

Fig. 2: Samples were centrifuged for 10 minutes at $4000 \mathrm{rpm}$

The liquid was discarded, after which, the product was washed 2 times with a small amount of methanol. Finally, the remaining solid was picked up with $15-20 \mathrm{~mL}$ of UP-water and sonicated for $\sim 5 \mathrm{~min}$ for uniform dispersion of the solid. The solid/UP-water mixture was frozen with liquid nitrogen in a test tube for 10 minutes then placed in jar used in a vacuum freeze-drying apparatus.

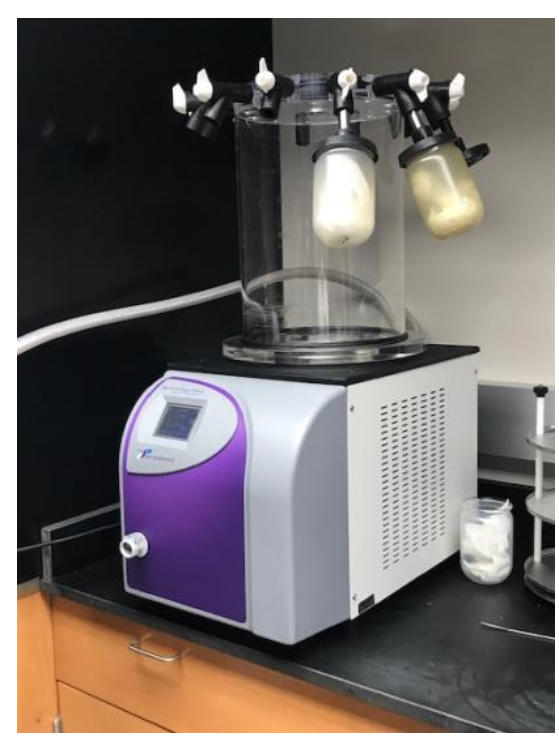

Fig. 3: Frozen sample in freeze-dry apparatus

Sampling was done for 5 consecutive days starting on day 4 of the experiment. Each sample was studied with $\mathrm{XRD}$ and TEM in order to identify the characteristics of $\mathrm{SnO}_{2}$. 


\section{RESULTS AND DISCUSSION}

The first sample was taken on day 4 of the experiment. As seen in Figure 4, the solution had developed a bright yellow tint compared to the previously white solution (see Figure 1).

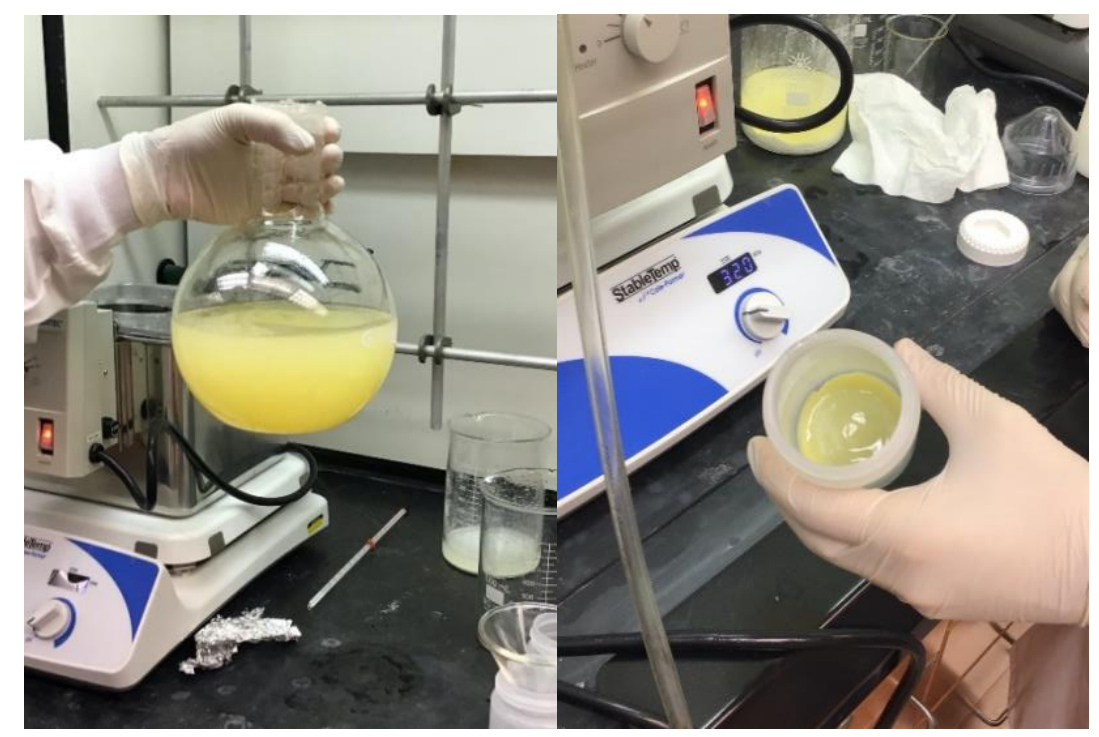

Fig. 4: $\mathrm{SnO}_{2}$ solution on day 4 of the experiment presented a bright yellow, cloudy appearance (left). After centrifuging, the sample had a lighter yellow, gel-like appearance (right).

The second sample was taken on day 5 of the experiment. Figure 5 shows the yellow color of the solution and the product produced after centrifuging. With this sample, there appeared to be more solid product after centrifuging than on day 4 .

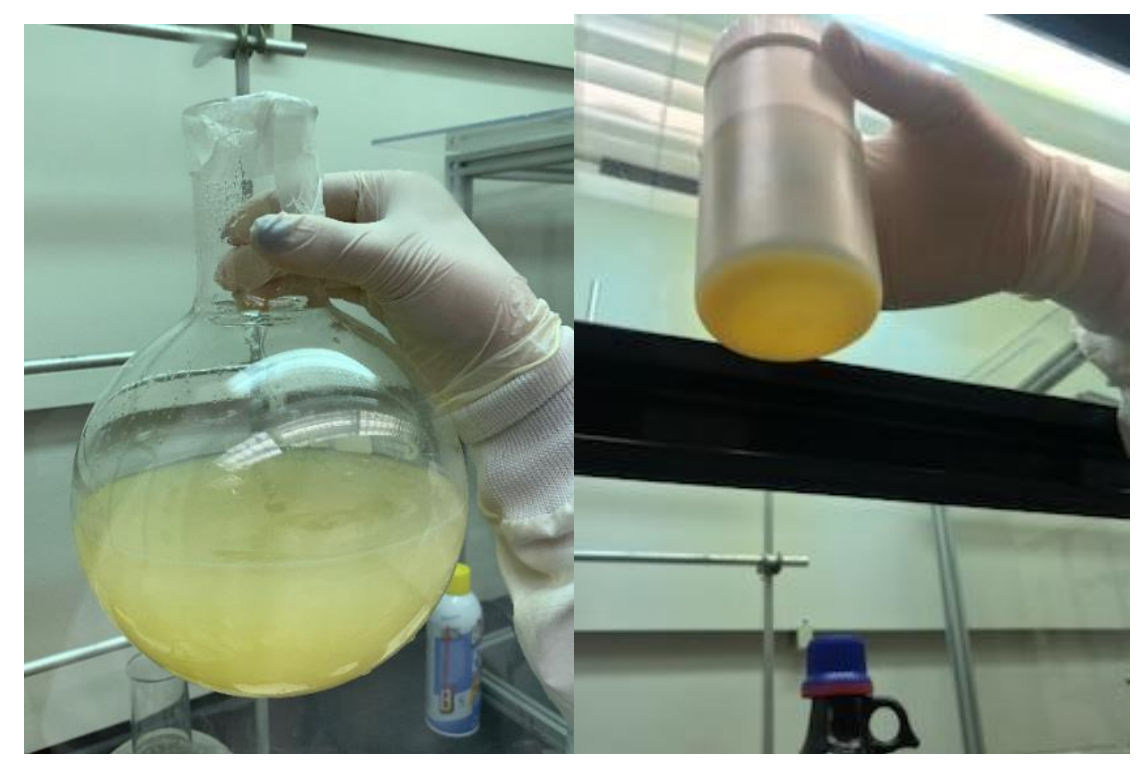

Fig. 5: $\mathrm{SnO}_{2}$ solution on day 5 of experiment (left). More solid produced after centrifuging than previous day (right).

On Day 6 of the experiment another sample was taken from the solution with the color seen Figure 6 . The product after centrifuging appeared to be a larger amount than the sample taken on day 5 . 


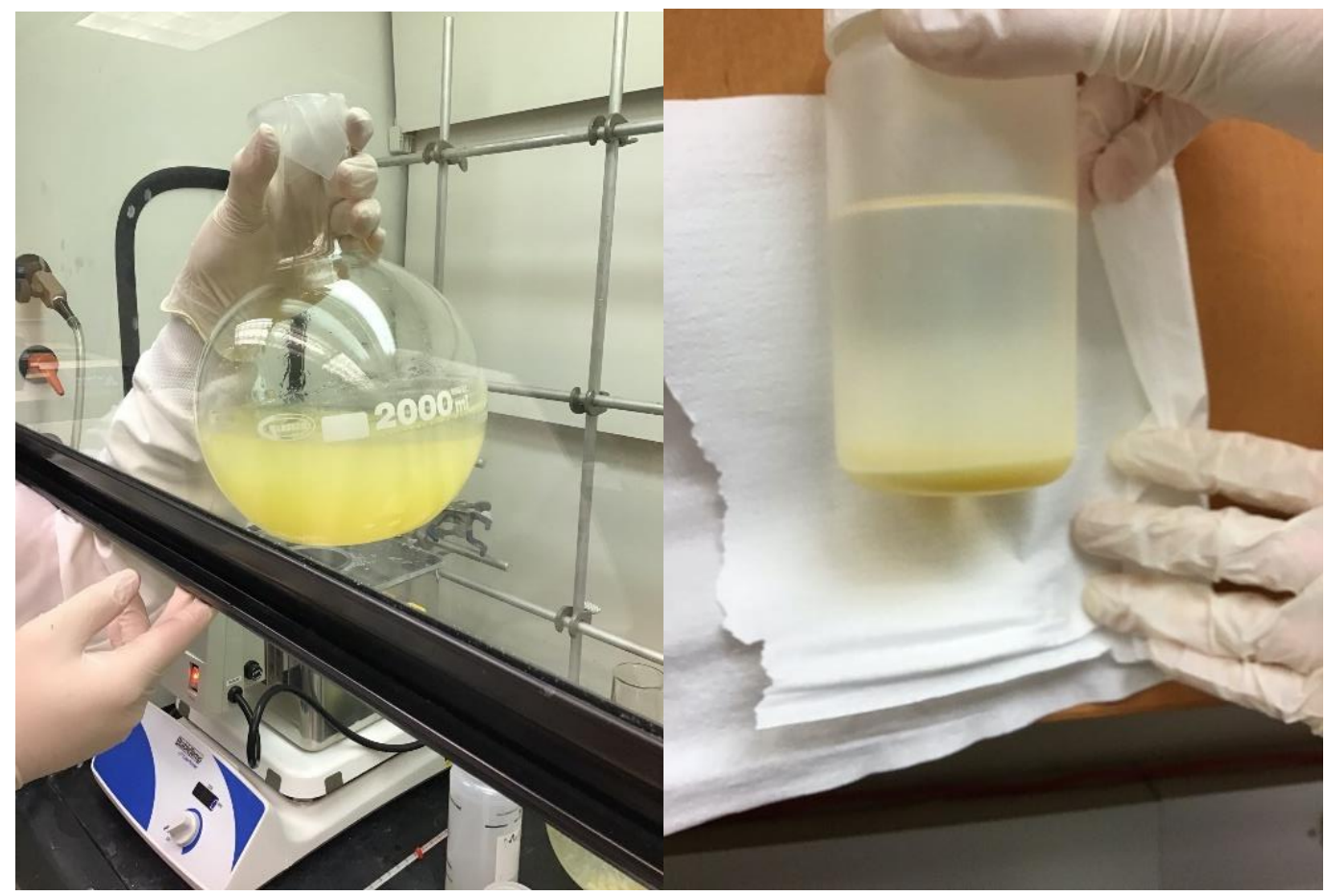

Fig. 6: $\mathrm{SnO}_{2}$ solution on day 6 of experiment (left). More solid produced after centrifuging than previous day (right).

To identify the size of the $\mathrm{SnO}_{2}$ particles on this day, TEM was performed on the dried sample. The results produced from this test can be seen in Figure 7.

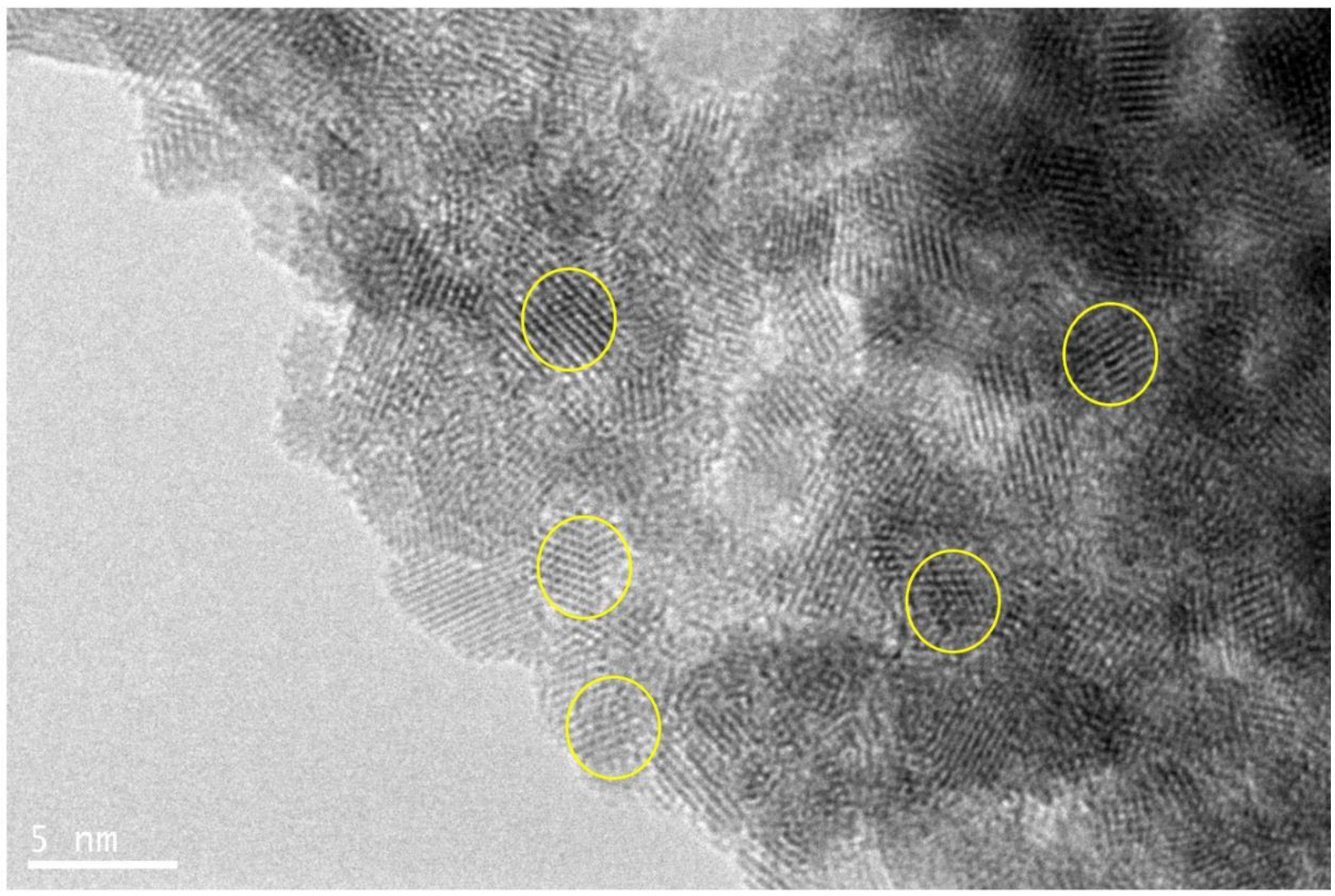

Fig. 7: TEM of day 6 sample. Yellow circles indicate fringe interplanes. 
On Day 7 of the experiment another sample was taken from the even darker yellow solution, as seen in Figure 8 .

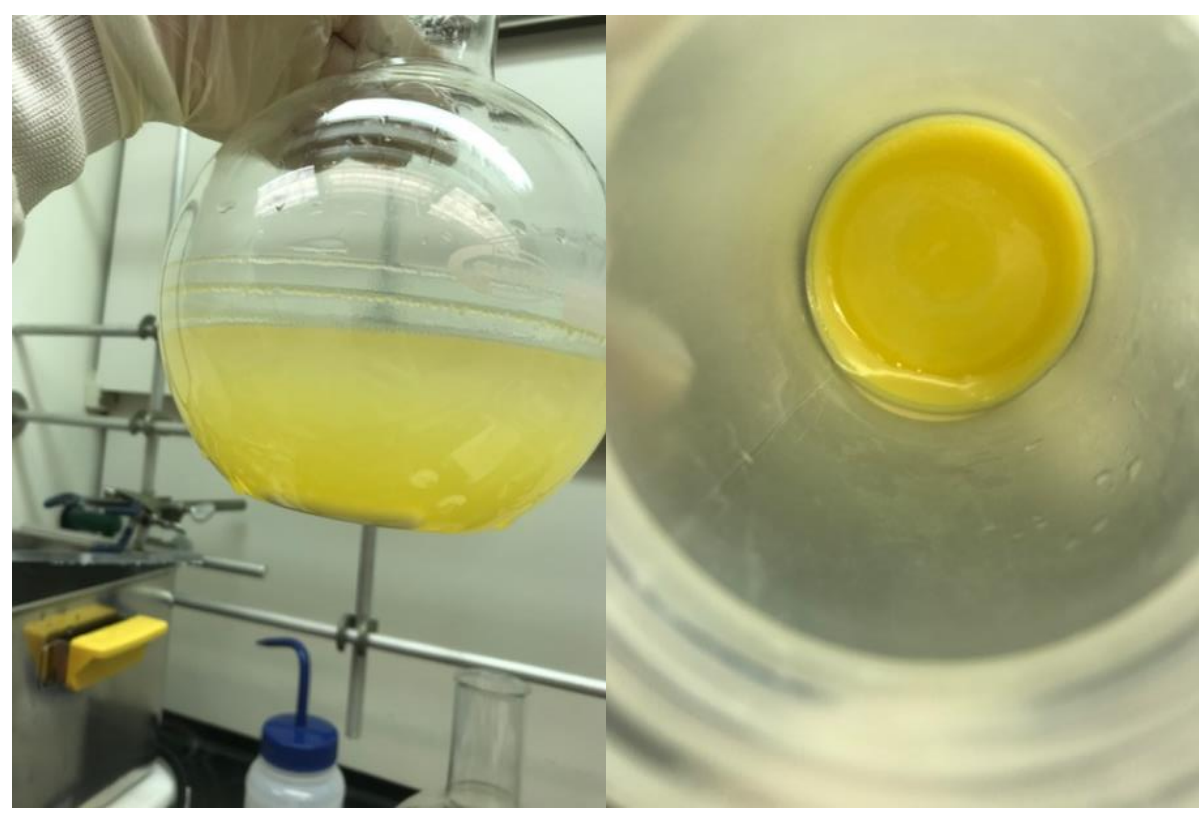

Fig. 8: $\mathrm{SnO}_{2}$ solution on day 7 of the experiment (left). Sample produced more of a thicker, darker product after centrifuging than previous day (right).

For the final day of sampling, on day 8 of the experiment, all the remaining solution was used, and the color can be seen in Figure 9.

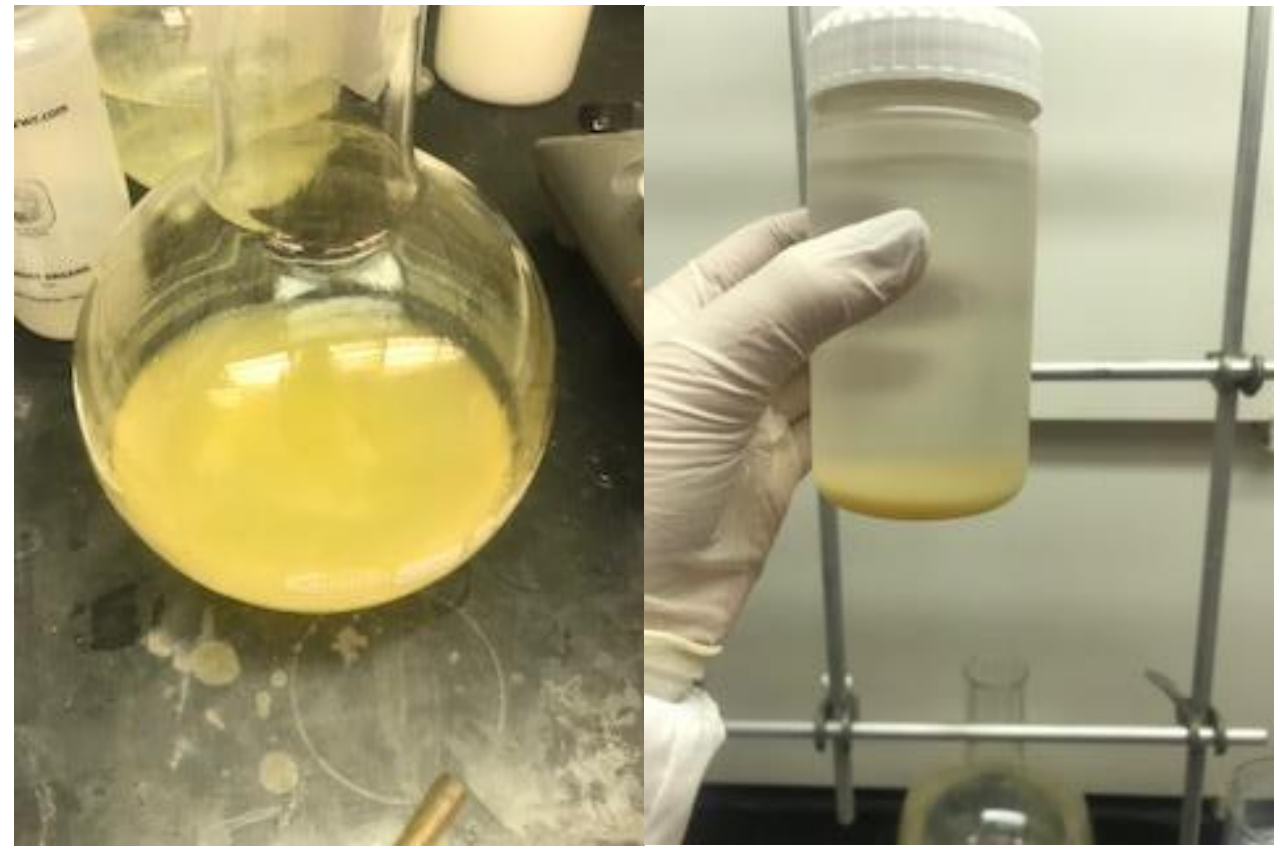

Fig. 9: $\mathrm{SnO}_{2}$ solution on day 8 (final day) of the experiment (left). Sample produced more product after centrifuging than any previous days (right)

To identify the size of the $\mathrm{SnO}_{2}$ particles, and whether the particles had increased in size from day 6 to day 8 , TEM was also performed on the day 8, dried sample. The results produced from this test can be seen in Figure 10. This TEM shows much larger particles than what can be seen in Figure 7 previously. 


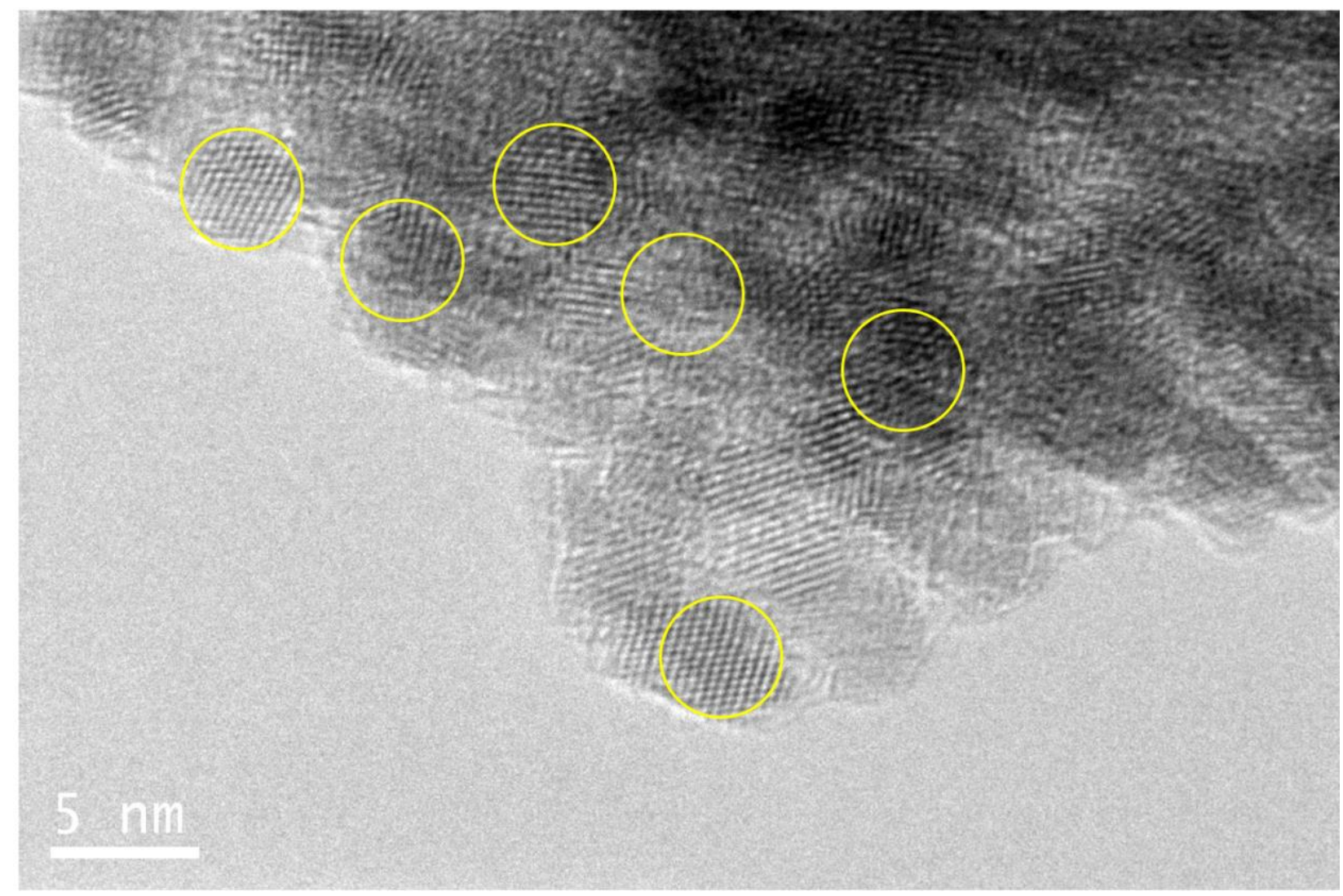

Fig. 5: TEM of day 8 sample. Yellow circles indicate fringe interplanes.

$\mathrm{XRD}$ was done on the samples from days 4, 6, and 8 to determine if any $\mathrm{SnO}_{2}$ nanoparticles were present in the samples. When compared to the standard $\mathrm{SnO}_{2} \mathrm{XRD}$ (Figure11), the peaks present in the XRD graphs confirmed that $\mathrm{SnO}_{2}$ was present in each of the three days that were analyzed (Figure 12).

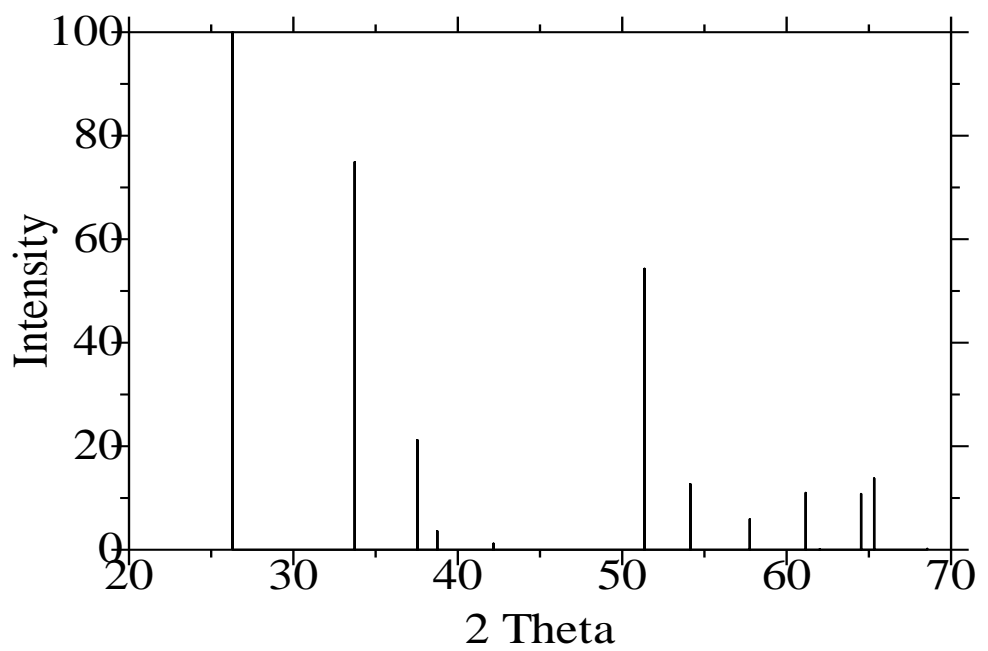

Fig. 11: $\mathrm{SnO}_{2}$ standard $\mathrm{XRD}$ graph. 

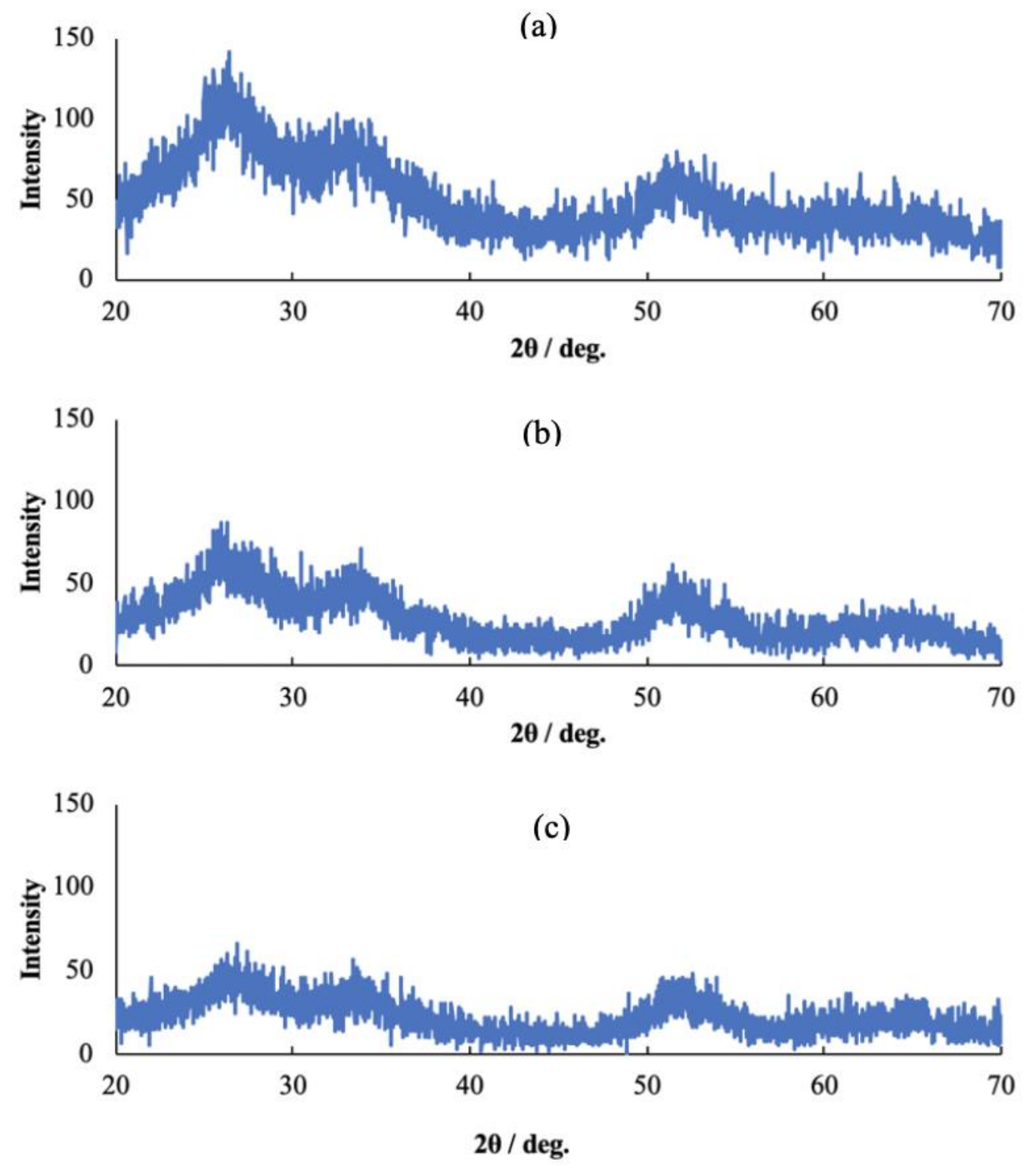

(a)

Fig. 12: Combined XRD taken a different sampling days, (a) after 4 days, (b) after 6 days, and (c) after 8 days.

\section{CONCLUSIONS}

We demonstrated that the low-temperature synthesis of $\mathrm{SnO}_{2}$, using freeze drying, was effective for obtaining crystalline $\mathrm{SnO}_{2}$ nanoparticles, as verified by XRD. From the results of this experiment it can be concluded that the $\mathrm{SnO}_{2}$ particles were present from the first day of sampling. Furthermore, the nanoparticles continued to gradually grow larger over the life of the experiment which allows the control of the particle's sizes. Currently, studies are on the way to determine the optimum size (synthesis time) to produce PSCs with the highest efficiency.

(b)

\section{ACKNOWLEDGMENT}

This work was supported by the Koshiyama Research Grant and JSPS KAKENHI Grant no. 15K05664 in Japan, Illinois Space Grant Consortium, USA., and Bradley University. 


\section{REFERENCES}

[1] Oh, J.-K., Lee, J.-K., Kim, H.-S., Han, S.-B., \& Park, K.-W. “TiO2 Branched Nanostructure Electrodes Synthesized by Seeding Method for Dye-Sensitized Solar Cells." Chemistry of Materials, vol. 22(3), pp. 1114-1118., (2010).

[2] Tański, T., Jarka, P., Szindler, M., Drygała, A., Matysiak, W., \& Libera, M. (2019). Study of dye sensitized solar cells photoelectrodes consisting of nanostructures. Applied Surface Science, 491, 807-813.

[3] Sofyan, N., Ridhova, A., Yuwono, A. H., Udhiarto, A., \& Fergus, J. W. "Synthesis of $\mathrm{TiO}_{2}$ nanoparticles at low hydrothermal temperature and its performance for DSSC sensitized using natural dye extracted from Melastoma malabathricum L. seeds." International Journal of Energy Research, vol.43(11), pp.5959-5968., (2019).

[4] Chen, H.-S., Su, C., Chen, J.-L., Yang, T.-Y., Hsu, N.-M., \& Li, W.-R. "Preparation and Characterization of Pure Rutile TiO2 Nanoparticles for Photocatalytic Study and Thin Films for Dye-Sensitized Solar Cells." Journal of Nanomaterials, vol.2011, pp.1-8., (2011).

[5] Yang, D., Yang, R., Wang, K., Wu, Cu., Zhu, X., Feng, J., Liu, S. (2018). High Efficiency Planar-Type Perovskite Solar Cells with Negligible Hysteresis Using EDTA-Complexed $\mathrm{SnO}_{2}$.

[6] Liu, K., Chen, S., Wu, J., Zhang, H., Qin, M., Lu, X., Zhan, X. (2018). Fullerene Derivative Anchored SnO2 for HighPerformance Perovskite Solar Cells.

[7] Yi, H., Wang, D., Mahmud, M. A., Haque, F., Upama, M. B., Xu, C., Uddin, A. (2018). Bilayer SnO2 as Electron Transport Layer for Highly Efficient Perovskite Solar Cells.

[8] Xie, H., Yin, X., Liu, J., Guo, Y., Chen, P., Que, W., Gao, B. (2018). Low Temperature Solutio-derived $\mathrm{TiO}_{2}-\mathrm{SnO}_{2} \mathrm{Bilayered}$ Electron Transport Layer for High Performance Perovskite Solar Cells. 